\title{
DEVELOPMENT OF SMART UNDERFREQUENCY LOAD SHEDDING SYSTEM
}

\author{
Vladimir Chuvychin — Roman Petrichenko*
}

\begin{abstract}
The paper describes possibility to apply innovation technology of Smart Grid for power system emergency automation. Operational characteristics of existing emergency automation and new suggested one are compared in the paper. The method for liquidation of drawback of existing automation is suggested. The paper describes the developed mathematical model of intellectual underfrequency load shedding system and its operational algorithms.
\end{abstract}

K e y w or d s: smart grid, optimization of emergency automation, underfrequency load shedding system

\section{INTRODUCTION}

Emergency automation is a major part of the power system. The operation of any emergency automation is based on the metering of certain parameters and reaction corresponding to the operational algorithm. Many types of emergency automation and control systems are used in the power system. They differ with functionality, design, etc. Some types of emergency automation use simple equations, other types - complex algorithms. However, they all have one common initial condition - receiving of information.

The rapid development of information technology's tendency of recent years makes it possible to obtain and process the large amounts of information during minimum time. Thus, appears possibility to improve the operation and functionality of the existing emergency automation.

In this paper the existing emergency automation, also known as underfrequency load shedding (UFLS), and the proposed smart underfrequency load shedding (SUFLS) emergency automation are described.

The imbalance between active power generation and consumption is directly reflected in a system frequency deviation [1].

Dynamics of underfrequency during the deficiency of generation in the power system can have very different characters. It depends on the value of disturbance, response of emergency automation, governor system and reasons of emergency situation [2]. The reasons for the occurrence of high-level active power imbalances may be a sudden change in the system load, the sudden outage of a large generating unit or the sudden outage of transmission lines. To restore frequency load shedding or spinning reserve involvement may be activated $[3,4]$.

The consequences of smaller imbalances ("low-level imbalances") are taken over by the turbine governors across the system, included in the primary frequency control. The frequency decay rate in such situations gives the turbine governor enough time to react accordingly. But when imbalances reach higher levels ("high-level imbalances") governor action cannot activate spinning reserve quickly enough to restore the system to its normal operating frequency, frequency actuated automatic load shedding (UFLS) serves as a last-resort tool to prevent the system from collapse [5]. UFLS system can be categorized into three groups [5]:

- the traditional UFLS system;

- the semi-adaptive UFLS system;

- the adaptive UFLS system.

Up-to-date traditional automatic load shedding system practically in the most power systems foresees disconnection without time delay or with small delay part of the load on underfrequency. The numbers of load shedding steps and value of load to be shed vary for the different power systems. Some power systems use rate-ofchange of frequency as additional factor to shed a load. Existing UFLS automation has drawbacks, which limit adaptability of emergency automation to a change of underfrequency situation in a power system. UFLS tripping frequency settings are selected for some specific emergency situation, which is considered more probable for specific power system and will be effective only for mentioned calculated emergency cases.

It is not possible to foresee all situations that can occur in the power system. The drawback of traditional UFLS is that value of shedded load sometimes does not coincide with the value of active power deficiency. As consequence of this imbalance overfrequency or frequency hovering situations can occur $[6,7]$

Below example of behavior for traditional UFLS system will be presented as well as new emergency automation approach. The aim of this paper is illustration of

* Faculty of Power and Electrical Engineering, Riga Technical University, Kronvalda boul. 1, Riga, Latvia, chuvychin@eef.rtu.lv, romans.petricenko@rtu.lv 


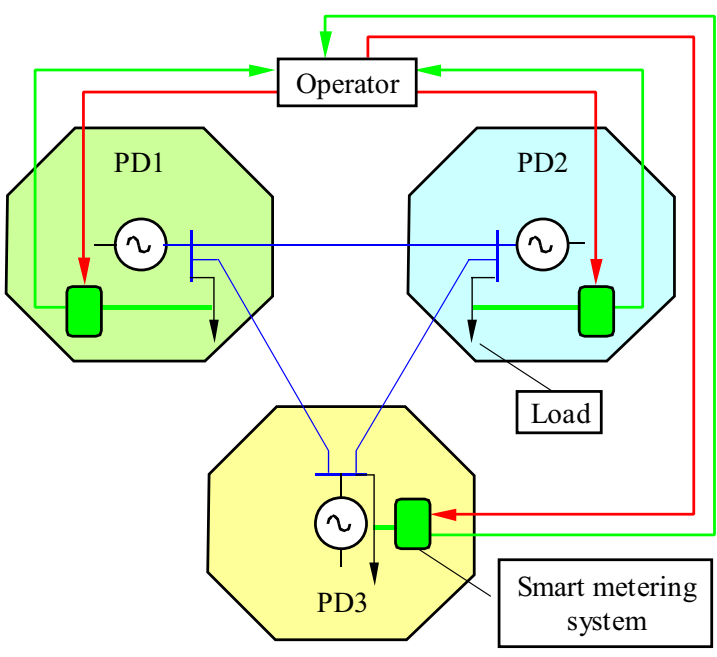

Fig. 1. Simplified diagram of interconnected power districts

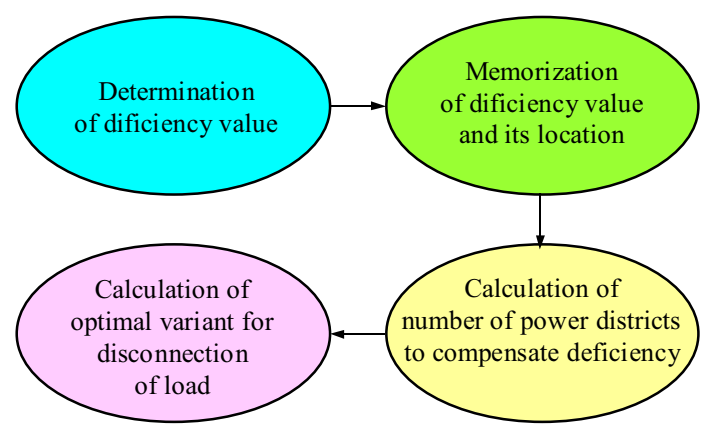

Fig. 2. Operation cycles of automation SUFLS

integration of smart grid technology into emergency automation and investigation the control process for such automation.

\section{SMART UNDERFREQUENCY LOAD SHEDDING SYSTEM (SUFLS)}

During the last few years the term "smart grid" is constantly used in different engineering fields. There are many papers describing application of smart grid technology in the fields of distribution, information and communication technologies, transmission and generation. A lot of papers describe the possibility to create centralized control systems. These systems have different types of construction and functionality [5]. Such systems integrate smart grid base technology, known as the smart metering system $[8,9]$. This technology is applying of interactive meters in a centralized system. Interactivity of device provides information about the current level of load and control of load (load shedding and restoration). Application of this technology enriches capacity of a full and precise control of the power system in normal and emergency network conditions $[10,11]$.

Power system can be divided into few parts (power districts). An example of the studied power system is shown in Fig. 1. Considered power system consists of three power districts. Each power district is equipped with an interactive measuring device that is connected to the information center "Operator". Moreover, these devices can be equipped with measuring blocks of active power deficiency. Devices react to the presence of deficiency in the power system. Knowing the precise value of deficiency can optimize operation of existing UFLS system.

Transformed rotor swing equation can be used for calculation of deficiency $[4,6,7]$ :

$$
\Delta P=T_{J} \frac{\mathrm{d} f}{\mathrm{~d} t}+\frac{\Delta f}{k_{\mathrm{stat}}}+\Delta f k_{\mathrm{reg}},
$$

where $\Delta f=\frac{2 \pi f-2 \pi f_{0}}{2 \pi f_{0}} . T_{J}-$ is the rotor's inertia constant; $k_{\text {stat }}$ - is the governor speed droop; $k_{\text {reg }}-$ is the load-damping constant; $f$ - is the frequency.

Assume that the operation of automation can be described using the example of appearance the deficiency equal to $0.8 \mathrm{pu}$, at the first power district.

So, automation operational process SUFLS can be presented by few calculation cycles: determination of deficiency value, memorization of deficiency value and its location, calculation of number of power districts, involved to compensate deficiency, calculation of optimal variant for disconnection of load feeders. The SUFLS operation cycles are shown in Fig.2. SUFLS system each time calculates the possibility of deficiency compensation and the optimal variant of the load shedding.

\subsection{Determination of deficiency value}

Equation (1) is used for determination of deficiency value.

\subsection{Memorization of deficiency value and its location.}

After point 2.1 appropriate smart meter registers value of deficiency and transmits its location.

\subsection{Calculation of number of power districts to compensate deficiency}

Thus, the automation fixes occurrence of deficiency, its size and location. The next step is the calculation of amount of power districts, involved in compensation of determined deficiency. For this purpose the block diagram of calculation algorithm "AL-1" is used, which is shown in Fig. 3.

Using centralized interactive metering technology, information center "Operator" continuously receives information about the current level of generation and consumption. The algorithm calculates the possibility of deficiency compensation by disconnection of available load (hereafter referred to $P_{\text {AvLoad } i}$ ) at the first power district. 


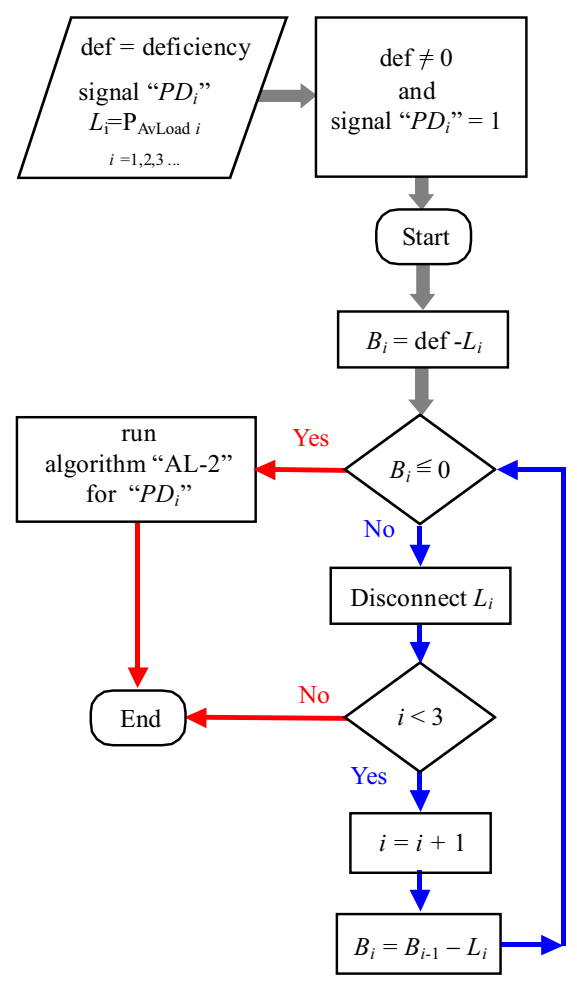

Fig. 3. Flowchart of algorithm "AL-1"; $P D_{i}-$ numbers of power districts; $L_{i}=\sum P_{i}-$ total load power of $1^{\text {st }}, 2^{\text {nd }}, 3^{\text {rd }}$ power districts; $B_{i}$-residual value of the deficiency; $i$ - number of power districts; def - value of deficiency

In other words, if the deficiency level does not exceed the load value $P_{\text {AvLoad1 }}$ at the first power district, the algorithm generates a signal for the following flowchart "AL-2" (calculation of optimal variant for disconnection of load) activation. In case when the deficiency value exceeds the amount of load $P_{\text {AvLoad1 }}$ at the first power district, the algorithm "AL-1" generates command to shed all load, available for compensation, at the first power district and calculates the residual value of the deficiency $B_{1}$. Then algorithm calculates the ability to compensate the deficiency residual value $B_{1}$ by the load $P_{\text {AvLoad2 }}$ at the second power district. The calculation is as long as the deficiency of active power will not be fully compensated. In this example, is assumed that the deficiency is fully compensated by the load shedding of first power district.

\subsection{Calculation of optimal variant for disconnec- tion of load}

Creating operational algorithm "AL-2" it was assumed that maximal number of load feeders is ten at each power district connected to the smart metering technology. The main objective of algorithm "AL-2" is the forming of matrix for possible combinations of load powers to determine the optimal value of disconnected load. Let us explain of aforesaid.

Consumers at each power district can be explained

$$
\mathrm{a}, \mathrm{b}, \mathrm{c}, \mathrm{d}, \mathrm{e}, \mathrm{f}, \mathrm{g}, \mathrm{h}, \mathrm{k}, \mathrm{l}
$$

For determination the number of variants of disconnected load equation (2) can be used [12]

$$
C_{n}^{k}=\frac{n !}{k !(n-k) !}
$$

where $n$ is the number of elements $(n=10) ; k$ is the number of combinations. $k=1,2, \ldots 10$.

Thus general number of variants for disconnected consumers $i$

$$
\sum_{\mathrm{var}}=\sum_{i=1}^{n} C_{n}^{i}=1023 \text { var. }
$$

Algorithm "AL-2" calculates 1023 variants of combinations of consumers. Next step is calculation the minimal difference (error $\delta$ ) between deficiency value and disconnected power load of corresponding variant

$$
\delta=|\operatorname{def}-z|
$$

where def - value of deficiency; $z$ - combinations array of consumers' powers.

Then for minimal value of $\delta$ algorithm "AL-2" creates operational signal to disconnect corresponding consumers. In such a way selection of optimal combination of disconnected consumers takes place.

\section{CASE STUDY}

To compare results of operation of traditional UFLS and SUFLS automations the mathematical models have been constructed using Matlab Simulink software [13, 14]. Behavior of frequency during different emergency situations is presented. Fig. 4 illustrates frequency behavior at emergency situation of power system which consists of three energy districts (Fig. 1). Network parameters are shown in Tab. 1. Emergency situation for power instant deficiency $\Delta P=0.8$ pu at the first power district at the time moment $t=0.0 \mathrm{~s}$ was simulated. Comparison of UFLS system and SUFLS system shows advantage of new suggested automation system. During operation of UFLS system frequency hovering takes place at the level of $49.33 \mathrm{~Hz}$. During operation of SUFLS system short decline of frequency to $49.82 \mathrm{~Hz}$ level is observed. It should be noted that the precision of the SUFLS automation depends on the discreteness of the disconnected load at each power district. Speed of load shedding depends on the type of circuit breakers. In this paper, assumed that gasinsulated circuit breakers, with operating time $t \sim 0.05 \mathrm{~s}$ are used.

The operation of proposed automation has been also tested at cascade emergency situation. As emergency situation two consequent disturbances were simulated: power instant deficiency at the second and the third power district at time $t=0 \mathrm{~s}$ and $t=150 \mathrm{~s}$. The assumed active power deficiency value is $1.12 \mathrm{pu}$ and $1.22 \mathrm{pu}$ respectively. 


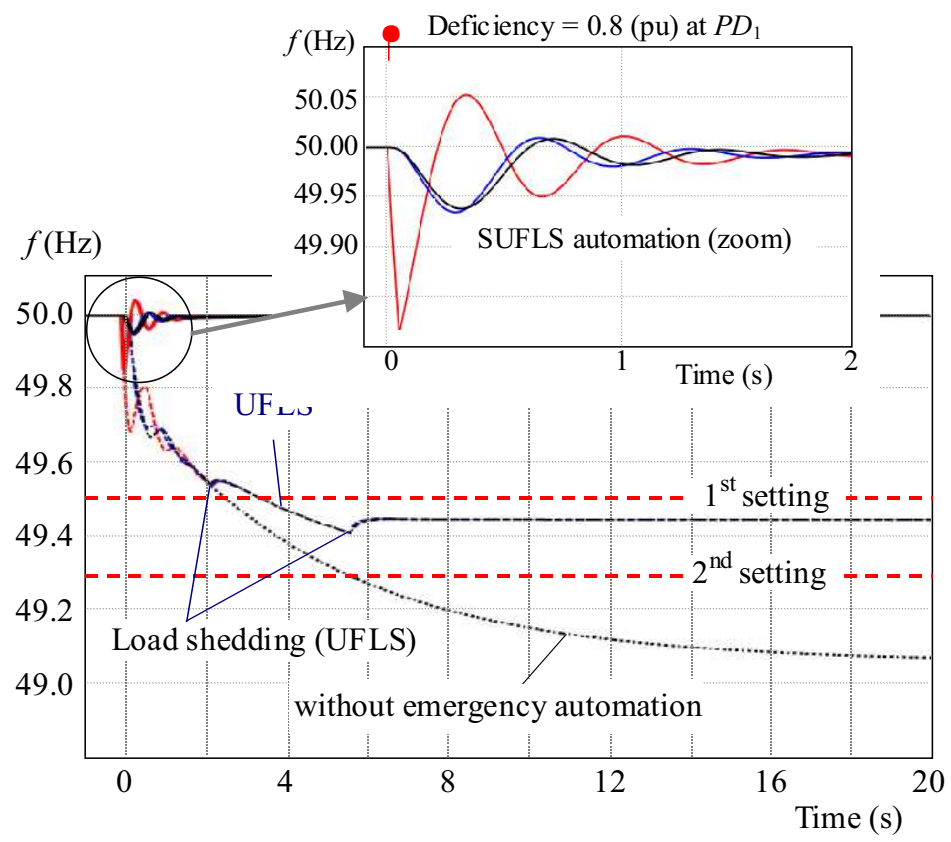

Fig. 4. Frequency behavior without load shedding automation, with UFLS automation and with SUFLS automation

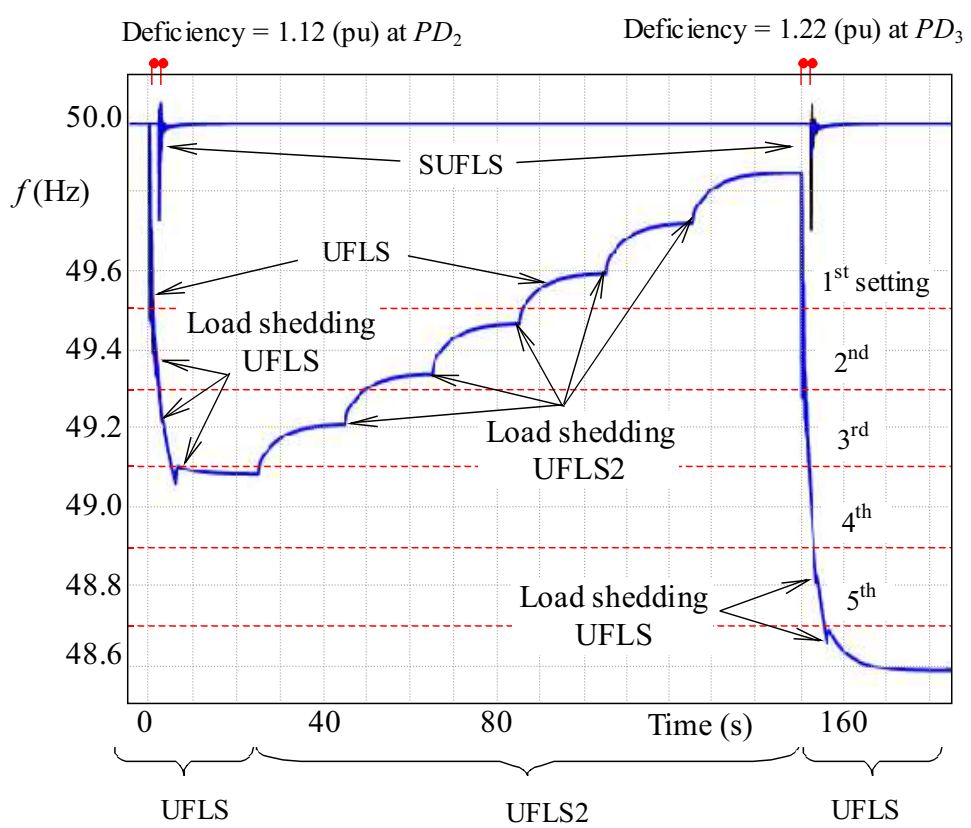

Fig. 5. Frequency behavior with UFLS automation and with SUFLS automation

Table 1. Parameters of network

\begin{tabular}{cccccc}
\hline $\begin{array}{l}\text { Power } \\
\text { district }\end{array}$ & $\begin{array}{c}\text { Generation } \\
(\mathrm{pu})\end{array}$ & $\begin{array}{c}\text { Load } \\
(\mathrm{pu})\end{array}$ & $\begin{array}{c}\text { Not available } \\
\text { load }(\mathrm{pu})\end{array}$ & $\begin{array}{c}\text { Available } \\
\text { load }(\mathrm{pu})\end{array}$ & $\begin{array}{c}\text { Maximal admittance of } \\
\text { transmission-line }(\mathrm{pu})\end{array}$ \\
\hline PD1 & $P_{\mathrm{G} 1}=1.0$ & $P_{\mathrm{Load} 1}=2.5$ & $P_{\text {NotAvLoad1 }}=0.5$ & $P_{\text {AvLoad1 }}=2.0$ & $P_{\max 1-2}=1.25$ \\
PD2 & $P_{\mathrm{G} 2}=1.5$ & $P_{\mathrm{Load} 2}=1.0$ & $P_{\text {NotAvLoad2 }}=0.1$ & $P_{\text {AvLoad2 }}=0.9$ & $P_{\max 2-3}=1.00$ \\
PD3 & $P_{\mathrm{G} 3}=2.5$ & $P_{\text {Load3 }}=1.5$ & $P_{\text {NotAvLoad3 }}=0.2$ & $P_{\text {AvLoad3 }}=1.3$ & $P_{\max 3-1}=1.20$ \\
\hline
\end{tabular}

Figure 5 shows the behavior of the power system's frequency using the existing emergency automation UFLS and the proposed emergency automation SUFLS.
The dashed horizontal lines show automation UFLS settings. Frequency values of the $1^{\text {st }}, 2^{\text {nd }}, 3^{\text {rd }}, 4^{\text {th }}$ and $5^{\text {th }}$ UFLS automation's steps respectively are $49.5,49.3$, 
49.1, 48.9, 48.7 Hz. When frequency crosses UFLS automation settings load shedding takes place. As seen from Fig. 5, at time $t=0$ disconnection of part of generation takes place. Let us consider frequency behavior when traditional UFLS is operating.

During this operation the frequency drops to $49.1 \mathrm{~Hz}$ and hovers at this level. Then frequency restoration is simulated (UFLS2). After restoration frequency hovering at level $49.88 \mathrm{~Hz}$ takes place. At time $t=150 \mathrm{~s}$ the additional loss of power generation at the third power district is simulated. As can be seen from the Fig. 5, at the frequency drop it overcomes three settings of UFLS automation, ie only $4^{\text {th }}$ and $5^{\text {th }}$ settings are activated.

Operation of SUFLS automation was simulated also. In this case frequency deep drop is not observed. SUFLS automation chooses optimal variant of disconnected load at the first and second occurrences of active power deficiency. As result of SUFLS operation frequency does not drop below $49.72 \mathrm{~Hz}$. Accuracy of SUFLS automation operation is better than traditional UFLS.

\section{CONCLUSIONS}

- The drawback of traditional UFLS is that value of shedded load sometimes does not coincide with the value of active power deficiency. As consequence of this imbalance overfrequency or frequency hovering situation can occur.

- New method of load shedding is suggested. Simulations were conducted for analysis for frequency behavior for existing and new load shedding system.

- The advantages of SUFLS automation are: suggested load shedding system is more effective emergency automation system than traditional underfrequency load shedding; new emergency automation allows to prevent deep frequency drop during generated deficiency condition; for large united power system suggested frequency control algorithm can be implemented for different power system districts separately.

\section{Acknowledgement}

This work has been supported by the European Social Fund within the project "Support for the implementation of doctoral studies at Riga Technical University".

\section{REFERENCES}

[1] KUNDUR, P.: Power System Stability and Control, McGraw-Hill, New Delhi, 1994.

[2] KOSCHEJEV, L. : Control of Emergency Automation in Power System, Energoatomizdat, 1989. (in Russian)

[3] BERKOVICH, M.-GLADISHEV, V.: Power System's Automation, Energoatomizdat, 1991. (in Russian)

[4] BARZAM, A.: System's Automation, Energoatomizdat, 1986. (in Russian)

[5] RUDEZ, U.-MIHALIC, R. : Analysis of Underfrequency Load Shedding Using a Frequency Gradient, IEEE Trans. Power Syst. 26 No. 2 (Apr 2011), 565-575.

[6] CHUVYCHIN, V.-GUROV, N.-VENKATA, S.-BROWN, R. : An Adaptive Approach to Load Shedding and Spinning Reserve Control during Underfrequency Conditions, IEEE Trans. Power Syst. 11 No. 4 (Nov 1996), 1805-1810.

[7] CHUVYCHIN, V.-GUROV, N.-KIENE, S.: Application of New Emergency Control Principle in Power Systems, Proceedings of IEEE PowerTech 2009 Conference, Romania, Bucharest, 29 June - 2 July, 2009, pp. 1-6.

[8] NGUYEN, P. H.-KLING, W. L.-MYRZIK, J. M. A. : Power Flow Management in Active Network, IEEE Bucharest Power Tech Conference, Bucharest, Romania, 29 June - 2 July, 2009.

[9] BRUNO, S.-LAMONACA, S.-LA SCALA, M.-ROTONDO, G.-STECCHI, U. : Load Control through Smart-Metering on Distribution Networks, IEEE Bucharest Power Tech Conference, Bucharest, Romania, 29 June - 2 July, 2009.

[10] PILO, F.-PISANO, G.-SOMA, G. G.: Advanced DMS to Manage Active Distribution Networks, IEEE Bucharest Power Tech Conference, Bucharest, Romania, 29 June - 2 July, 2009.

[11] LEMMEN, H.: SMART Transmission System, IEEE Smart Grid World Forum (presentation), Brussels, Belgium, 2-3 December, 2010.

[12] BABICH, N.-ZHUKOV, I. : Circuit Technology of Computers, MK - express, Moscow, 2004. (in Russian)

[13] DJAKONOV, V.-PENJKOV, A.: Matlab and Simulink in Power Systems, Hot-line Telecom, 2009. (in Russian)

[14] PORSHNEV, S. : Matlab 7 basic of programming, Binom-Press, 2011. (in Russian)

Received 2 May 2012

Vladimir Chuvychin was born in Russia, in 1941. He received Engineer (1964) and $\mathrm{PhD}$ (1974) degrees in Electrical Engineering from the Riga Polytechnical institute, Latvia. In 1994 Vladimir Chuvychin received Dr habil Sc ing from the Riga Technical University, Latvia. His area of interests is protective relaying and power system emergency automation. Now he is a professor of Faculty of Electrical and Power Engineering at Riga Technical University.

Roman Petrichenko was born in Latvia, in 1986. He received MSc degree in Electrical and Power Engineering from the Riga Technical University in 2010. Currently he is a 3-rd year PhD student and a researcher at the Faculty of Electrical and Power Engineering. His research interests are smart grids, emergency automation and control systems. 